SVU- International Journal of Veterinary Sciences, 2 (1): 75-81, 2019.

Print ISSN: 2535-1826

\title{
The Potential of Nutrigenomics from Viewpoint of Animal Nutrition: A Mini Review Bimrew Asmare $^{1^{*}}$ and Tesfaye Negewo ${ }^{2}$
}

${ }^{1}$ Bahir Dar University, Department of Animal Production and Technology, Bahir Dar, P.O. Box 5501, Bahir Dar, Ethiopia, ${ }^{2}$ Education Strategy Center, Addis Ababa, Ethiopia.

\section{Abstract}

Nutrigenomics is relatively new area of science which requires more appraisal and further research. Therefore, it must be well understood before it is applied in the field of agriculture particularly in animal science. From earlier few studies, it has been learnt that nutrigenomics and allied sciences have significant importance to serve as modern tool for nutritional research in comprehending the problems related to animal production and health. But the level of awareness is not that much raised for maximum exploitation of the science. For this reason, efforts have to be exerted to uncover the state of current knowledge, skill and practices how nutrigenomics helps in boosting animal productivity and health condition. One of the approaches to expand this knowledge is using various dissemination mechanisms such as bringing together the information from different sources, analyzing and interpreting. In scientific or research language, this is referred as review. To this end, literature and articles related to animal nutrition and health which were produced over several years are browsed and reviewed. Based on the review, it is possible to recognize that the future of animal nutrition requires intensified feeding and precise nutrient specification of animals. Hence, understanding the importance of nutrigenomics, exploring how it works, and identifying what benefit it has is the scope of the review. This piece of paper is therefore written to describe what nutrigenomics mean, its importance, how it can be applied and what contribution it has to the field of animal sciences.

Keywords: Deoxyribonucleic acid, Genes, Nutrition, Ruminant nutrition.

DOI: $10.21608 /$ svu.2019.7265.1005
Received: January 15, $2019 \quad$ Accepted: March 15, 2019
Published: March 19, 2019
*Corresponding Author: Bimrew Asmare
E-mail: limasm2009@gmail.com

Citation: Asmare and Negewo, The potential of nutrigenomics from viewpoint of animal nutrition: A mini review. SVU-IJVS 2019, 2 (1): 75-81.

Copyright: (C) Asmare and Negewo. This is an open access article distributed under the terms of the creative common attribution license, which permits unrestricted use, distribution and reproduction in any medium provided the original author and source are created.

Competing interest: The authors have declared that no competing interest exists 


\section{Introduction}

The genome is the entire deoxyribonucleic acid (DNA) sequence of an organism including structural genes, regulatory sequences and non-coding DNA sequences. The human genome is estimated to encode up to 30000 genes, and responsible for generating more than 100,000 functionally distinct proteins (Trujillo et al., 2006). Genomics is the systematic study of the genome and is an approach of mapping, sequencing, and analysis of all genes present in the genome focusing on resolving the variation in the genome between individuals (Cassar-Malek et al., 2008; Flench et al, 2011). Functional genomics aims to uncover both the functional roles of different genes and how these genes interact with and influence each other in the functional network underlying health and disease. With the completion of the Human Genome Project, it was realized that a new era in biological and medical sciences was beginning. This is often referred to as the 'omics' revolution (Mariman, 2006).

New technologies and knowledge from the Human Genome Project were combined with those of established scientific disciplines like pharmacology and toxicology. These combinations are leading to the terms 'pharmacogenomics' and 'toxicogenomics'. In the same manner, the introduction of genomics approach in nutritional sciences lead to the scientific area called 'nutrigenomics'. The nutrigenomics science is relatively new field of study that requires advancement since it is important in regulation of genes that affect performance of animals. Hence, the intent of this review is to briefly define nutrigenomics highlight how it impacts genes and its importance in the field of animal sciences particularly its application in animal nutrition.

\section{Approach}

This short review is conducted by gathering related information from various data sources through browsing different websites, reputable journal articles, and published and print materials. The analysis has involved twenty-eight scientific writings of which twenty one are directly talking about nutrigenomics in animal nutrition, production and health, whereas the rest are talking public health nutrition and research related to the field. From the literature, concept, the use and impacts of nutrigenomics from the view point of animal nutrition have been synthesized and finally conclusion has been drawn.

\section{Application of nutrigenomics in animal nutrition}

The conventional animal feeds and nutrition study and research largely focuses on correcting deficiencies, animal nutrient relations and responses of animals to specific feeds or nutrients. However, techniques like genomic revolution enables science of nutrition to be related to gene expression (Collins,et.al., 2003). Of the recent advances in omics, applications in animal nutrition are proteomic, metabolomic, and bioinformatics. These are now making their ways to solve the intervening puzzle between nutrient and genes (Daniel, 2002). Hence, understanding the current knowledge about nutrigenomics helps the farm animal nutrition process for efficient and up-to-date technological utilization. In this line, Tryhurn (2003) anticipated that the science of nutritional genomics could be one of the important areas in the study of nutrition as nutrients are dietary signals, detected by the cellular. The science of nutrigenomics has received much consideration these days due to its potential in preventing, mitigating and treating chronic disease and certain cancers. In the modern science, it has been documented that about 99.9\% of human genomes are identical and there is only $0.01 \%$ difference that occurs due 
to single nucleotide polymorphisms (SNPs). According to Thorisson and Stein (2003), there are about 3.1 million SNPs with high polymorphic nature present in human genome that create variability among individuals. This SNP database can be used to identify genetic variants within population. Moreover, some types of cancer and cardiovascular diseases are among the most evident pathologies sensitive to nutritional modulation (Kant, 2004; Sales et al., 2014). Cognizant to this, appreciation of the food risk factors is important which will help to diminish the impact of such noncommunicable destructive health factors in population.

The activities of genes are regulated by the signals of metabolic activities in the nucleus which intern are controlled by hormones, and environmental factors such as nutrients (Harland, 2005). With this regard, research in nutrition has given attention to the function of nutrients on gene expression and its regulation in the animal body (Müller et al., 2003; Chavez, et.al.2003; Ghormade et al., 2011; Fenech et al., 2011). Reen et al. (2015) indicated that nutrient is not simply a chemical element in cell or tissue but it is involved in a function to regulate gene expression (Fig. 1). In the figure, nutrients may act directly as ligands for transcription factor receptors (pathwayA); may be metabolized by primary or secondary metabolic pathways, thereby altering concentrations of substrates or intermediates (pathway B) involved in gene regulation or cell signaling; or alter signal transduction pathways and signaling (pathway $C$ ).

The science of genomic research in the areas of proteomic and metabolomic techniques have made possible the understanding of nutrients in food elements, to enable defining the function of nutrientgene interaction at the cell and individual level. Nutrigenomics is the appreciative sense that enables professionals in the field to know how nutrients determine the genetic expression of individuals (Chadwick, 2004; Kaput et al., 2005). The science of nutrigenomics helps in identifying important nutrients such as amino acids, digestive enzymes, hormones, etc which can be synthesized in the animal.

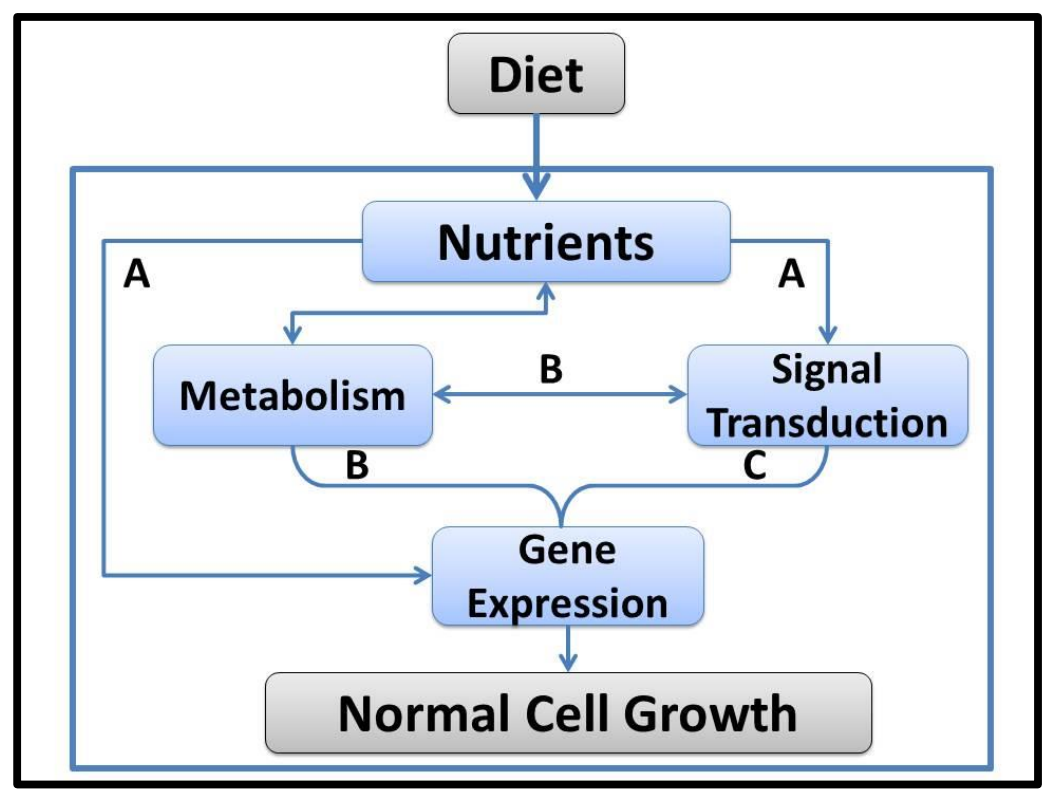

Fig. 1. Fate and activities of nutrients in the cell. Source: Reenet al.2015 


\section{Importance of nutrigenomics in of animal production, reproduction and health}

Application of nutrigenomics has a number of advantages in animal nutrition including the feed efficiency, yield of animals, reproduction efficiency and improving of animal immune systems. The possible application of nutrigenomics was reviewed by different authors (Zduńczyk and Pareek, 2008; Pal, 2018). Among the components of nutrigenomics, transcriptomics and metabolomics are the potential techniques used to efficiently understand the molecular actions taking place in a genome receiving nutritional signals and responding to them through characteristic metabolic processes in the organism.

The nutrient requirement for maintenance and production varies according to genetic variation which enables to apply selection to choose superior animals for feed efficiency (Carstenset al., 1989). The review of Ghormade et al. (2011) and Benítez et al. (2017) indicated that the application of nutrigenomics helps to properly manage nutrients and with the gene of the animal, control the interaction of nutrients with the gene and help to understand how nutrients regulate reproduction. Mudasir et al. (2018) describes that the nutrition of animals particularly in aquatic animals, the expression of genes can be altered through modification feeding. From a practical point of view, gene expression studies allow for the identification of pathways and candidate genes responsible for economically important traits (Castiblanco et al., 2018). Dietary manipulations and nutritional strategies are key tools for influencing ruminant production. There is a usual belief that nutrition and genetic makeup both strongly influences the reproductive performance of milk animals. This is particularly important during the transition period and early lactation when the animal is particularly sensitive to nutritional imbalances. In addition, in a report of Mondal et al. (2016), the application of nutrigenomics, particularly proteomics enhances gene expression in growing animals and improves growth performance.

In the shifting situation of animal nutrition, the study of nutrigenomics helps to understand how nutrients and gene expression interact in relation to production and reproduction of animals. A study conducted on steers exposed to restricted nutrition of low-quality feeds has shown that the effects of gene expression were influenced in that steers were not able to respond due to anatomical and physiological stresses of limiting nutrients (Byrneetal., 2005). Moreover, a study conducted by Rao et al. (2001) elucidated that this notion of nutrigeomics and study of diet induced gene expression is discovered in which selenium deficiency shown to alter protein synthesis at transcriptional level. Pajović (2008) also elaborated that nutrients can interact with the genome and modify subsequent gene expression.

Another study indicated that the regulation of milk fat content in dairy cows can be affected as genes could discern a pattern of those genes that regulate fat digestion and absorption, and which had the most significant influence on milk fat (Krag, 2013). The discovery of gene markers which are related to economically important traits like milk, meat, and wool production etc. whose expression can be improved by dietary regimens is a need of today's nutrigenomic research which will help for sustainable livestock production. The science of nutrigenomics has been given more attention in nutrition studies as it is believed that nutrigenomics has a potential to help producing immune system to certain disease and can be way to treat completely chronic diseases like cancer. A general study conducted by Tellez et al. (2014) indicated that nutrigenomics is the connection that 
directly correlates food with animal health and determines the phenotype of an individual.

These studies are good indicators to illustrate that nutrigenomics can be used to identify the specific markers to maneuver gene expression through use of nutrients or their combinations so as to improve productive as well as overall animal potential or performance. In general, the future of nutrition in animals seems to be better dependent on the science of nutrigenomics as it would be instrumental for identification of pathways and candidate genes responsible for dietary induced diseases and ultimately reduction in production losses due to the effects of diseases in animals. These past studies can be fairly taken as virtuous indicators of the potential of nutrigenomics to control diseases and ensure health of individuals, and the current state of knowledge could be springboard for future applied research in animal sciences.

\section{Conclusion}

This piece of review indicated that nutrigenomics will be a potential to serve as modern tool for nutritional research in mitigating the problems related to animal production and health. Therefore, more knowledge and understanding on how nutrients influence every physiological process in the animal body will be an advantage for nutritional management. Hence, the future innovations in nutritional research with use of various molecular technologies will undoubtedly bring up to date understanding of nutrient gene interrelationship and help to define new methods for managing animal production. Finally, by targeting the specific gene through nutritional manipulation, it may be possible to get the desired livestock performance in terms of health as well as production.

\section{References}

Benítez R Núñez Y Óvilo C (2017). Nutrigenomics in Farm Animals. J Investig Genomics 4(1): 00059. DOI: 10.15406/jig.2017.04.00059

Cassar-Malek I Picard B BernardCHocquette JF (2008). Application of gene expression studies in livestock production systems:a European perspective, Australian Journal of Experimental Agriculture48:701-710.

Castiblanco V Castillo, HE,Miedaner $\mathrm{T}$ (2018). Candidate Genes for Aggressiveness in a

Natural Fusariumculmorum Populatio n Greatly Differ between Wheat and Rye Head Blight. J. Fungi 4, 14.

Carstens GE, Johnson DE, Johnson KA, Hotovy SK, Szymanski TJ (1989). Genetic variation in energy expenditures of monzygous twin beef cattle at 9 and 20 months of age.Energy Metabolism of Farm Animals. EAPP Publ. Pudoc, Wageningen, The Netherlands. Page 312.

Chavez A, Muñoz de, Chavez M (2003). Nutrigenomics in public health nutrition: short-term perspectives Eur. J. Clin. Nutr., 57 (Suppl-1): S97-S100. Chadwick R (2004). Nutrigenomics, individualism and public health. The Proceedings of the Nutrition Society 63, 161--166.

Collins FS, Green ED, Guttmacher AE,Guyer MS (2003). A vision for the future of genomics research Nature, 422: 835-47.

Daniel H. (2002). Genomics and proteomics: importance for the future of nutrition research 
Br. J. Nutr., 87(Suppl. 2):305-1131.

Fenech M., El-Sohemy A., Cahill L., Lynnette R., Tapaeru-Ariki F C. Frenchc E ShyongTaie John, Milnerd Woon-PuayKohf Lin Xieg Michelle Zuckera Michael Buckleya Leah Cosgrovea Trevor Locketta Kim YC Funga R., (2011). Nutrigenetics and Nutrigenomics: Viewpoints on the Current Status and Applications in Nutrition Research and Practice, J Nutrigenet Nutrigenomics, 4:69-89.

Ghormade V. Khare A, BaghelRPS(2011). Nutrigenomics and its Applications in Animal Science, Veterinary ResearchForum, 2(3): 147-155.

Harland JI (2005). Nutrition and genetics. Mapping individual health. ILSI Europe Concise Monograph Series.

Kant AK (2004). Dietary patterns and health outcomes. J. Am. Diet. Assoc., 104: 615-635.

Kaput J, Ordovas JM, Ferguson L (2005). The case for strategic international alliances to harness nutritional genomics for public and personal health. Brit J Nutr., 94:623-32.

Krag K (2013). Genetic parameters for milk fatty acids in Danish Holstein cattle based on SNP markers using a Bayesian approach BMC Genetics 14: 79-89.

Marco-Ramell A, de Almeida AM, Cristobal $\mathrm{S}$, Rodrigues $\mathrm{P}$, Roncada $\mathrm{P}$, and Bassols A, (2016). Proteomics and the search for welfare and stress biomarkers in animal production in the one-health context, Mol. BioSyst.,12: 2024

Mariman, ECM (2006). 'Nutrigenomics and nutrigenetics: the 'omics' revolution in nutritional science' Biotechnology and
Applied Biochemistry, vol. 44(3):119128.

Mondal M, Ghosh MK (2016). Application of nutrigenomics for enhancement of body growth in ruminants. Research \& Reviews: Journal of Veterinary Science and Technology. 5(1): 1-6p.

MudasirMaqsood Hakim, Nazir Ahmad Ganai, Syed Mudasir Ahmad, OyasAsmi, TowseefAkram,

Müller M, Kersten S (2003). Nutrigenomics: goals and strategies. Nature Reviews Genetics. 4(4):315.

Pajović B S (2008). Nutrigenomics. Genetika, Vol. 40, No. 1: 67-74.

Pal Aruna, (2018). Nutrigenomics- An Emerging Area".Acta Scientific Nutritional Health 2(9): 12-13.

ReenJagishKour,YadavAlok Kumar and Singh Jitendra (2015). Nutrigenomics: concept, advances and applications, Asian J. Dairy \& Food Res, 34(3): 205212.

Sales NMR, Pellegrini, Goersch MC (2014). Nutrigenomics: Definitions and advances of this new science. J. Nutr. Metab., Vol. 2014. 10.1155/2014/202759.

Shafat H., Nadeem S., Riaz Shah and Adnan Hussain Gora (2018). Nutrigenomics: Omics approach in aquaculture research to mitigate the deficits in conventional nutritional practices, Journal of Entomology and Zoology Studies6(4): 582-587.

Tellez G, Latorre JD, Kuttappan VA, Kogut MH, Wolfenden A (2014). Utilization of rye as energy source affects bacterial translocation, intestinal viscosity, microbiota composition and bone 
mineralization in broiler chickens. Front Genet 5: 339.

Thorisson, GA, and Stein LD (2003). The SNP consortium website: past, present and future. Nucleic Acids Res., 31: 124-127.

Trujillo M E, Willems A, Abril A, Planchuelo A M, Rivas R, LudenA D, MateosP F, Martı' nez-Molina E, Vela' zquez E (2006). Ochrobactrumlupini sp. nov. In List of New Names and New Combinations Previously Effectively, but not Validly, Published, List no. 110. Int J Syst Evol Microbiol 56, 14591460.
Trayhurn P (2003). Nutritional genomics Nutrigenomics". Brit. J. Nutr. 89, 1-2 Trayhurn P (2003). Nutritional genomics Nutrigenomics". Brit. J. Nutr. 89, 1-2 Zduńczyk Z,PareekChS(2008). Application of nutrigenomics tools in animal feeding and nutritional research, Journal of Animal and Feed Sciences, 17, 3-16 